attention a 'forgotten woman in a man's world' is passé in the early twenty-first century. However, I think the author is justified on other grounds. With almost all of Bate's personal records, such as diaries or photographs, having been lost, destroyed or perhaps never made, Shindler has focused instead on the work of a scientist of considerable ability, originality and resourcefulness. Perhaps it is today's almost voyeuristic obsession with the analysis of motives and feelings, and the cult of personality, that leads us to expect a biography to address such issues - especially as the subject is female, and therefore 'ought' to have recorded her innermost feelings. I certainly don't keep any such diaries, and I wonder how many of my fellow scientists do.

In this biography, then, we are dealing first and foremost with a scientific record. In the end, it is the results of her research - the new specimens, species and their descriptions that stand the test of time. I am grateful to Shindler for bringing Bate and her work to my attention.

Jennifer Clack is at the University Museum of

Zoology, Downing Street, Cambridge CB2 3EJ, UK.

\title{
A Stone Age greenhouse
}

Plows, Plagues and Petroleum: How

Humans Took Control of Climate

by William F. Ruddiman

Princeton University Press: 2005. 272 pp.

$\$ 24.95, £ 15.95$

\section{Robert J.Charlson}

The activities of Stone Age farmers may have altered Earth's climate. This is the exciting but controversial theory conveyed by palaeoclimatologist William Ruddiman in his wellwritten book Plows, Plagues and Petroleum.

I am not a climatologist, but my work on atmospheric chemistry, aerosols and cloud physics relates to Ruddiman's analysis of Earth's climate over the past few millennia. Aerosols and clouds must be included in any analysis of palaeodimate because they are so variable and exert such a powerful influence on the albedo of the planet. It cannot be assumed that they remained constant over this time. I strongly support Ruddiman's view that fitting all these pieces together to figure out the key cause-and-effect relationships "makes studying climate history fun".

Ruddiman's book is unusual because he candidly describes his main ideas as a thesis rather than as fact, and states that they are currently being debated in refereed publications. This high level of candour will certainly be appreciated by scientists, and the book's descriptive analogies and lack of jargon make it accessible to the lay reader as well.

The book starts with the importance of climate to human history, the basic science of climate, the connections between Earth's orbit and climate, and the modulation of ice ages, monsoon circulations and climate, with "nature in control".

The main thesis then emerges, with a description of the inexorable changes imposed by humans on the chemical composition of Earth's atmosphere. Starting with Ruddiman's strongest scientific argument, the increase of the greenhouse gas methane about 5,000 years ago is attributed to Stone Age farming. Simple calculations of the amount of methane generated per person by flood irrigation, animal

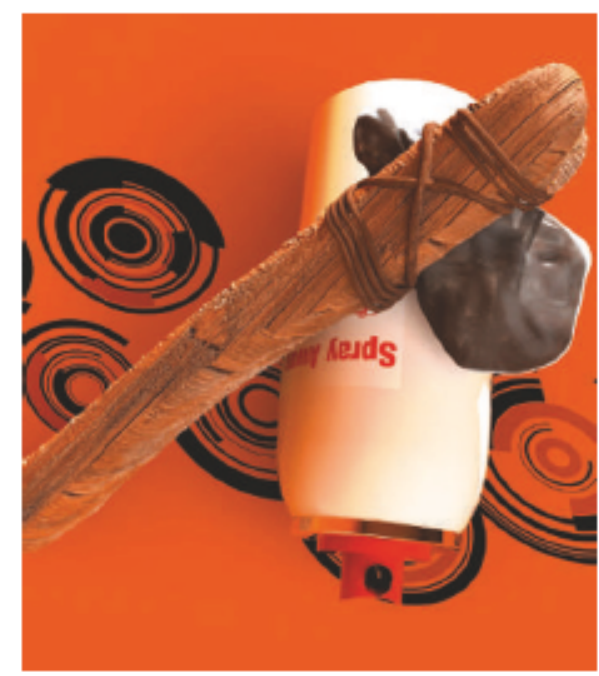

husbandry and biomass burning show emission rates high enough to explain the methane data obtained from ice cores.

Other population-based estimates for the emission of carbon dioxide, another greenhouse gas, show that over a period of several thousand years, enough biomass combustion could have occurred during land clearing to increase the concentration by the observed amount, 40 parts per million. Stone Age humans apparently began burning forests about 8,000 years ago, which fits with the time series of carbon dioxide data.

Moving from the data-based analysis of rising levels of methane and carbon dioxide to the tentative business of climate forecasting, Ruddiman then asks: ${ }^{\alpha}$ Have we delayed a glaciation?" He thinks we have, arguing that the stability of the climate over the past 10,000 years " may have been an accident". The warmth of the past several thousand years "stems from a colossal coincidence: a natural cooling" that was "offset by a human-induced warming".

Then, in what almost seems to be an afterthought, the small 'wiggles' in the carbon dioxide record and a decrease in the rate of its increase over the past 2,000 years are interpreted to have been caused by the decimation of human populations in epidemics and pandemics. Smaller populations produced less carbon dioxide, adding yet more variables to the study of palaeodimate.

The main part of the book concludes with three chapters on the nature of climate in a future with "humans in control". Ruddiman provides a vivid description of the immensity of human influence on the climate and on the environment in general. The growth of greenhouse gases is singled out, with carbon dioxide and methane being dominant. The paradoxically small observed temperature increase in the industrial period (about $0.6^{\circ} \mathrm{C}$ ), compared with the larger rise of $0.8^{\circ} \mathrm{C}$ caused by previous human activity, is attributed to a delay in climate response and to cooling factors generated by humans, such as sulphate aerosols.

Current global warming is then analysed over a shorter time scale (centuries) by means of uncertain estimates of the future rate of carbon dioxide and methane emission by human activities. This shorter-term analysis is then set in the context of the distant past (with nature in control) and for several centuries in the future (under human influence), all properly labelled as uncertain.

An epilogue completes the book, in which Ruddiman presents his own views on the issues of climate change. He decries the habit in the press of wanting "clever, crisply phrased sound bites" and he laments the polarization regarding global warming. He calls for recognition of the underlying reality that ${ }^{\alpha} \mathrm{draconian}$ economic sacrifices" will be needed, and that this should put the global-warming debate "in a dearer perspective". So ends an excellent book summarizing and placing in context the age-old influence of humans on atmospheric composition, dimate and global warming.

However, just as it is difficult to prove that Earth's warming over the industrial period has been caused by the emission of greenhouse gases through human activities, it is also difficult to prove that Stone Age farming caused a lack of cooling thousands of years ago. The debates about the causality of both present-day warming and the warming needed in the past to delay an ice age can be summarized briefly in terms of the concept of climate forcing, the imposed change in energy balance. For causality of global warming to be demonstrated, three interconnected premises must hold: the anthropogenic global forcing must be positive and substantial in magnitude; the temperature change must be positive and beyond the range of natural variability; and the former must be the cause of the latter.

If Ruddiman used the concept of forcing to strengthen and refine his thesis, he could address more specifically the uncertainties in assigning the causality of temperature increases to Stone Age agronomists. He could find further reasons for the higher sensitivity of temperature to early changes in methane and carbon dioxide levels. He would have to consider smoke from biomass burning as a 
cooling factor - might it have played a role in causing the little ice age?

The debate continues among climatologists, but it would seem that Ruddiman must be at least partly correct: there can be no question that Stone Age farmers added methane and carbon dioxide to the atmosphere, but how much and when? The debate, which seems to centre on the interpretation of details of temperature inferences from isotopic records in sediments and ice cores, cannot disguise the fact that levels of both methane and carbon dioxide began to increase long before the onset of industrialization.

Robert J. Charlsonis in the Department of Atmospheric Sciences and the Department of Chemistry, University of Washington, Seattle, Washington 98125, USA.

\section{Sticking with nature}

\section{The Gecko's Foot. Bio-inspiration: Engineered from Nature. by Peter Forbes \\ Fourth Estate: 2005.272 pp. $€ 20$}

\section{R. McNeill Alexander}

Biomimetics is the application of ideas from nature in engineering. At first sight, it seems a promising approach: evolution by natural selection is extremely effective, and designers can surely learn from its solutions. But so far, biomimetics has not achieved very much. As recently as 2003, Julian Vincent, professor of biomimetics at the University of Bath, UK, and one of its keenest proponents, wrote that "the only successful examples I know of are Velcro (1955) and the Anglepoise lamp".

I would discount the Anglepoise lamp. Its springs will support it in any position, much as the elastic ligament in a cow's neck supports its head, but I know of no evidence that the lamp designer knew about the cow. Velcro is more convincing. Its inventor, George de Mestral, got the idea from burs that stuck to his dog's

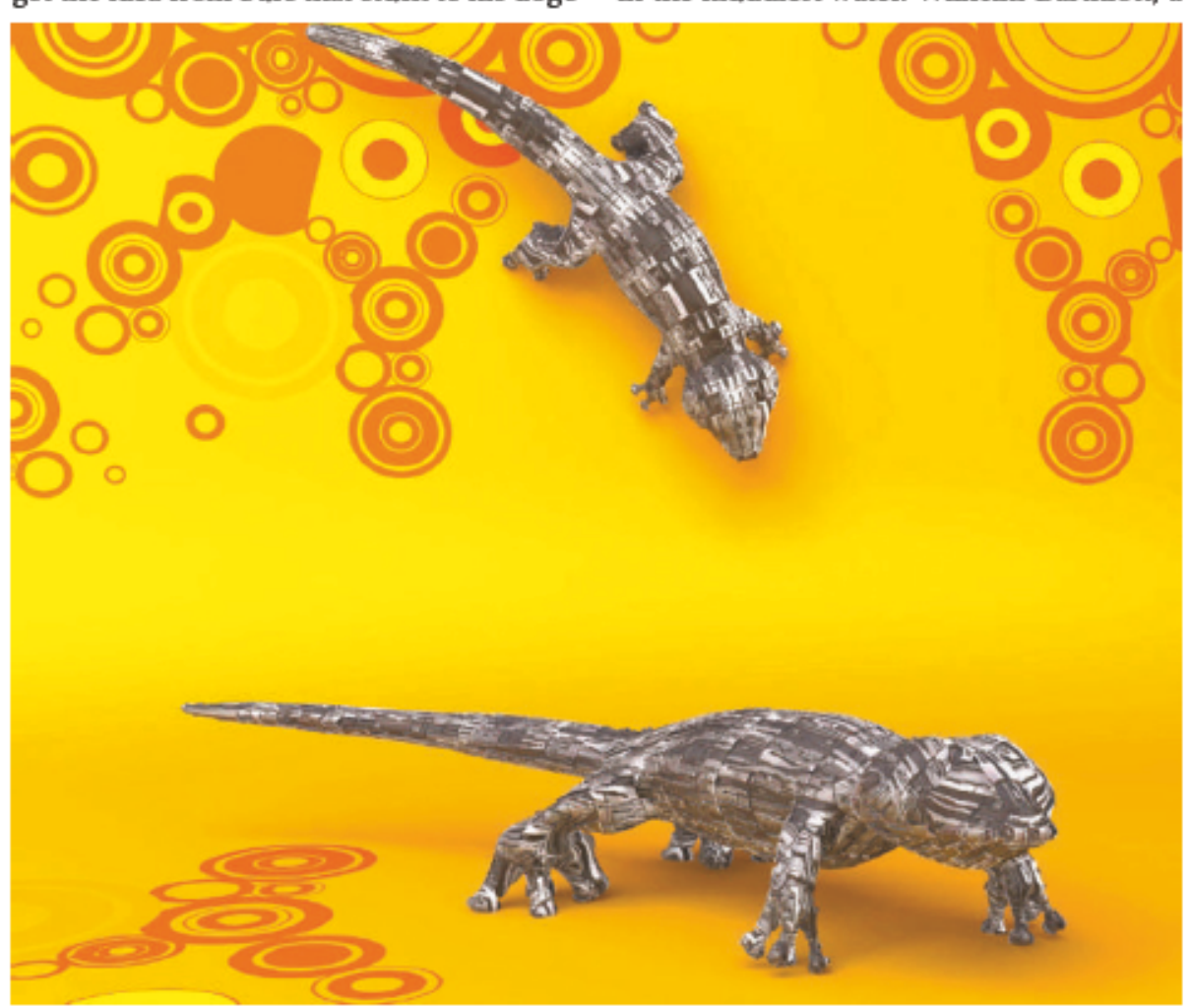

botanist at the University of Bonn, Germany, discovered that these leaves are covered in tiny hydrophobic tubercles, in the blind-zone range of sizes. On this surface, water forms almost spherical drops, and rolls off as if from a duck's back, carrying dirt away with it. (The duck's back works on the same principle.) Barthlott persuaded a paint company that the lotus effect, as he called it, had commercial potential, and they developed a paint for the outside of buildings. It looks like ordinary paint but has a silicone surface that is rough in the blindzone scale. Rain keeps it beautifully clean.

Forbes continues with other examples. The gecko's foot, which gives his book its title, is covered with a carpet-like pile of hairs. The end of each hair has many branches a few hundred nanometres across. These hairs make such close contact with the surfaces on which the lizard walks that they adhere by intermolecular attraction (the van der Waals effect). This lets the gecko climb walls and even run across the ceiling. Adhesive tape working on the gecko principle has been made but not yet commercially developed.

Forbes discusses other examples in the size range that he thinks so promising, including the multilayer reflectors in the wings of iridescent butterflies and the self-assembling properties of bacteriophages but, as with the gecko, these are potential rather than realized commercial applications. He discusses some larger-scale effects, including the aerodynamics of insect flight and the folding pattern that enables a large leaf to be opened from a slender bud, but these are also of possible future value rather than current successes.

Forbes frankly admits that biomimetics has had few triumphs so far. He tells us in his final chapter: "I have written about science and technology on the hoof because this is a new science and success is a matter of decades of work. Rather than wait until some of these technologies have become commonplace, I have tried to capture the Wordworthian 'bliss-it-was-in-that-dawn-to-be-alive' moment of seeing what was, until 15 years ago, a wholly unexpected science taking shape before our eyes."

There is a great deal of interesting and unfamiliar material here, but I found some of the scientific explanations unsatisfactory. To quote one example, in the explanation of the lotus effect, the statement that "water sits on the points of the bumps, with the compression of the air in the cavities giving extrabuoyancy" is misleading: the effect depends on contact angles, not air pressure and buoyancy. On the other hand, an admirably comprehensive set of notes directs readers to the primary scientific literature. The general readers for whom this book is intended will enjoy it, and it will give them some appreciation of a fascinating field.

R. McNeill Alexander is in the Faculty of Biological Sciences, Miall Building, University of Leeds, Leeds LS2 9JT, UK. 